\title{
A comparative study of induction characteristics of thiopentone, midazolam and propofol in elderly patients
}

\author{
Md Enayet Karim ${ }^{1}$, Md Abdul Hye ${ }^{2}$, Md. Nazmul Ahsan ${ }^{3}$, Md Moinul Haque Chowdhury ${ }^{4}$, \\ Md Nurul Amin (Rtd) ${ }^{5}$, Md. Mustafa Kamal ${ }^{6}$
}

\begin{abstract}
${ }^{1}$ Graded specialist in Anaesthesiology, Combined military hospital(CMH), Dhaka, ${ }^{2}$ Professor and Chairman, Department of Anaesthesia, Analgesia and Intensive, are, Bangabandhu Sheikh Mujib Medical University, Dhaka, ${ }^{3}$ Adviser specialist in Anaesthesiology, CMH, Dhaka, ${ }^{4}$ Classified specialist in Anaesthesiology, CMH, Dhaka, ${ }^{5}$ Professor(C.C), Department of Anaesthesia, Bangladesh Medical College \& Hospital, ${ }^{6}$ Department of Anaesthesia, Analgesia \& Intensive Care Unit, BSMMU, Dhaka
\end{abstract}

Corresponding Author: Email: enayet852@yahoo.com

\begin{abstract}
Background Intravenous anaesthetic agents are used commonly to induce anaesthesia, as induction is usually smoother and more rapid than that associated with most of the inhalation agents. Thiopentone is the most widely used intravenous induction agent in current anaesthetic practice. Propofol (2,6 diisopropyl phenol) is a new rapidly acting intravenous anaesthetic. The rapid redistribution and metabolism of propofol, result in a short elimination half life. Midazolam is an imidazobenzodiazepine with relatively rapid onset of action and high metabolic clearance compared to other benzodiazepine.
\end{abstract}

Objectives This prospective study was carried out to compare the induction characteristics of thiopentone, midazolam and propofol in elderly patients.

Methods Ninety adult patients, aged between 60-80 years with ASA grade I \&II who were scheduled for general surgery in Bangabandhu Sheikh Mujib Medical University, CMH Dhaka and CMH Saidpur were included in this study. The patients were divided into three groups of thirty each according to a randomization table.The overall performance of the drugs were assessed by recording the following parameters: 1) Pain on injection. 2) Induction time ( The time from start of injection to the loss of eye lash reflex). 3) Coughing 4. Involuntary motor activity. 5. Apnoea (present/absent). 6. Haemodynamic changes (Heart rate and blood pressure at 2 min before injection, after induction and $1 \mathrm{~min}$, 3 min and $5 \mathrm{~min}$ after intubation). 7. Recovery time (From the end of reversal until the patient responded to vocal command(eye opening, tongue protrution).

Results The incidence of pain on injection was greater in propofol group(38\%), which was statistically significant $(p<0.01)$. The induction time was significantly longer $(p<0.001)$ in the midazolam group. Incidence of excitatory effects was more common in propofol group $(p<0.05)$. Incidence of apnoeic episodes were significantly greater in thiopentone and propofol group than midazolam group $(p<0.05)$. Propofol caused significant decrease in systolic, diastolic and mean arterial pressure at 3 \& 5 minutes after intubation $(p<0.001)$.Neither Thiopentone, midazolam nor propofol caused significant change in heart rate. Recovery time in midazolam group was significantly longer $(p<0.001)$.

Conclusion Thiopentone is the drug of choice for induction in elderly patients because of rapid induction, recovery and the least effect on arterial pressure. Propofol has no clear advantage over thiopentone and has the additional problem of a significant decrease in blood pressure. Midazolam, although safe, is clearly not the ideal drug for induction in elderly patients because of slow onset of action and delayed recovery.

Key words Induction agent, thiopentone, midazolam, propofol

(JBSA 2013; 26(1): 5-11) 


\section{Introduction}

Aging is accompanied by unavoidable decline in organ system function and responses to drugs. As part of the normal aging process, most organ system lose approximately $1 \%$ of their function per year beginning at around 30 years of age. ${ }^{1}$ Optimal anaesthetic management of elderly patients depends on an understanding of the normal changes in physiology, anatomy and response to pharmacologic agents that accompany aging.

Thiopentone is the most widely used intravenous anaesthetic agent in current anaesthetic practice. It has, however, a long half life, which makes it less than ideal for use in ambulatory patients and can result in accumulation when used in repeated incremental doses or as a continuous infusion. A further disadvantage of thiopentone is a tendency to cause hypotension, particularly in patients suffering from cardiovascular disease or hypovolaemia. ${ }^{2,3} \mathrm{~A}$ number of other agents have become available as possible alternatives. Propofol ( 2,6 diisopropyl phenol) is a new rapidly acting intravenous anaesthetic. The rapid redistribution and metabolism of propofol, resulting in a short elimination half life of approximately one hour suggest that the drug could be suitable for use in short procedure. ${ }^{2,3,4}$ Midazolam is a imidazobenzodiazepine. It is water soluble in acid formulation ( $\mathrm{pH}$ less than 4) but becomes highly lipid soluble at physiological $\mathrm{pH}$. It has a relatively rapid onset of action and high metabolic clearance compared to other benzodiazepines. $5,6,7$

The pharmacokienetic of drugs are frequently defined in groups of healthy, normal, young male volunteers. ${ }^{8,9,10}$ The patients to whom the drugs are subsequently administered therapeutically however, are often elderly with perhaps multiple disease processes. As far as the elderly patients are concerned, agents that cause least physiological interference with rapid recovery have to be chosen. It is therefore, important to evaluate the effects of age on drug disposition.

\section{Methods}

Ninety adult patients, aged $60-80$ years with ASA grade I \& II who were scheduled for general surgery in Bangabandhu Sheikh Mujib Medical
University(BSMMU), Combined Military Hospital(CMH),Dhaka were included in the study. The patients were divided into three groups of thirty each according to a randomization table. In the control group, 30 patients received thiopentone and designated as thiopentone group. Midazolam and propofol were administered to two other groups of patients for induction of anaesthesia and designated as midazolam and propofol group respectively. All the patients were premedicated with diazepam at the dose of $0.2 \mathrm{mg} / \mathrm{kg}$ body weight. After 3 minutes of preoxygenation anaesthesia was induced. The drugs were given through an $18 \mathrm{G}$ cannula in the dorsum of the hand. Thiopentone ( intended dose $4 \mathrm{mg} / \mathrm{kg}$ ), midazolam (intended dose $.2 \mathrm{mg} / \mathrm{kg}$ ) and propofol (intended dose $2 \mathrm{mg} / \mathrm{kg}$ body weight) were injected sufficiently slowly to keep the haemodynamic stability by assessing clinically the rate and volume of the radial pulse until loss of eye lash reflexes. A tracheal tube with an internal diameter of $8 \mathrm{~mm}$ in male $7 \mathrm{~mm}$ in female were inserted with the help of suxamethonium $1.5 \mathrm{mg} / \mathrm{kg}$ using macintosh size 4 blade. The overall performance of the drugs were assessed by recording the following parameters: 1) Pain on injection. 2) Induction time (time from the start of injection to the loss of eye lash reflex). 3) Coughing 4) Involuntary motor activity. 5) Apnoea (present/ absent). 6. Haemodynamic changes ( heart rate and blood pressure at 2 minutes before injection, after injection and 1 minute after intubation for 5 minutes). 7. Recovery time (from the end of reversal until the patient responded to vocal command - eye opening, tongue protrution). Halothane was stopped 15 minutes before reversal and time from the end of reversal until the patient responded to vocal command was recorded.

Results were expressed as mean \pm SD. For statistical analysis student's ' $t$ ' test, analysis of variance (ANOVA) and chi-square tests were applied where appropriate. Differences were considered statistically significant if $\mathrm{P}<0.05$.

\section{Results}

All the groups were comparable for age, sex, weight and duration of anaesthesia. Subject details are shown in Table I.

Table I Patient characteristics and duration of anaesthesia

\begin{tabular}{lccccc}
\hline Group & Weight $(\mathrm{kg})$ & Age $($ year) & Duration (hour) & Male & Female \\
\hline Thiopentone $(\mathrm{n}=30)$ & $54.3( \pm 3.2)$ & $68.3( \pm 6.3)$ & $1.5( \pm 0.4)$ & 23 & 7 \\
Midazolam(n=30) & $55.2( \pm 4.6)$ & $68.1( \pm 5.9)$ & $1.3( \pm 0.6)$ & 25 & 5 \\
Propofol $(\mathrm{n}=30)$ & $56.1( \pm 4.3)$ & $67.5( \pm 6.3)$ & $1.6( \pm 0.3)$ & 21 & 9 \\
\hline
\end{tabular}


The incidence of pain on injection is shown in Table II. The total incidence was greater in the group receiving propofol (38\%), than in that receiving thiopentone $(7 \%)$ and midazolam (3\%). This difference was statistically significant.

Table II Pain on injection

\begin{tabular}{lccccc}
\hline Group & Mild Moderate Severe Total & $\begin{array}{c}\mathrm{X}^{2} \\
\text { value }\end{array}$ \\
\hline Thiopentone & 2 & 0 & 0 & $2(7 \%)$ & \\
Midazolam & 1 & 0 & 0 & $1(3 \%)$ & 13.00 \\
Propofol & 5 & 3 & 3 & $11(38 \%)$ & \\
\hline
\end{tabular}

$\mathrm{P}<0.01$

The time to induction (time to loss of eye lash reflex) was similar in the propofol and thiopentone group but significantly longer $(p<0.001)$ in the midazolam group. This is shown in Table III.
Table III Induction time in seconds

\begin{tabular}{lcc}
\hline Group & Mean $( \pm \mathrm{SD})$ & F value P value \\
\hline Thiopentone & $31.8667( \pm 1.2243)$ & \\
Midazolam & $44.7000( \pm 4.3164)$ & $167.177 \mathrm{P}<0.001$ \\
Propofol & $31.1667( \pm 1.7633)$ & \\
\hline
\end{tabular}

The number of patients showing spontaneous movement and excitatory effects is shown in Table IV. The incidence of spontaneous movement was more common in the group receiving propofol $(p<0.05)$. Three patients all of whom received propofol, showed spontaneous movement and one other complication ( twitching, hypertonous, and hiccough).

Seven patients (25\%), each in the thiopentone and propofol groups, required assisted ventilation because of apnoeic episodes that lasted more than 15 seconds, 3 patients in the midazolam group had apnoea that lasted longer than 15 seconds. This is shown in Table V.

Table IV Incidence of excitatory effects

\begin{tabular}{lcccc}
\hline Group & Spontaneous & Twitching & Hypertonous & Hiccough \\
\hline Thiopentone & 1 & 0 & 0 & 1 \\
Midazolam & 2 & 0 & 0 & 1 \\
Propofol & 7 & 1 & 1 & 2 \\
\hline
\end{tabular}

Table V Incidence of apnoea after induction

\begin{tabular}{lccccc}
\hline & Thiopentone & Midazolam & Propofol & $\mathrm{X}^{2}$ value & P value \\
\hline Apnoea $>15 \mathrm{sec}$ & 7 & 3 & 7 & 6.882 & $\mathrm{P}<0.05$ \\
\hline
\end{tabular}

Changes in pulse rate from baseline (i.e before injection) are shown in Table VI. Neither thiopentone, midazolam nor propofol caused a significant change in heart rate.

Table VI Comparison of heart rate at different reading points

\begin{tabular}{lccccc}
\hline Group & $\begin{array}{c}2 \text { minutes } \\
\text { before } \\
\text { injection- } \\
\text { mean }( \pm \text { SD) }\end{array}$ & $\begin{array}{c}\text { after } \\
\text { induction- } \\
\text { mean }( \pm \text { SD) }\end{array}$ & $\begin{array}{c}\text { 1minute } \\
\text { after } \\
\text { intubation- } \\
\text { mean }( \pm \text { SD })\end{array}$ & $\begin{array}{c}\text { 3minutes } \\
\text { after } \\
\text { intubation- } \\
\text { mean }( \pm \text { SD })\end{array}$ & $\begin{array}{c}\text { 5minutes } \\
\text { after } \\
\text { intubation- } \\
\text { mean }( \pm \text { SD })\end{array}$ \\
\hline Thiopentone & 75.0667 & 79.0667 & 85.0000 & 75.5333 & 74.9333 \\
Midazolam & $( \pm 2.1645)$ & $( \pm 2.1645)$ & $( \pm 4.4644)$ & $( \pm 2.5962)$ & $( \pm 2.4202)$ \\
& 74.9000 & 78.8333 & 86.6333 & 75.2667 & 75.1667 \\
Propofol & $( \pm 2.0401)$ & $( \pm 1.9667)$ & $( \pm 6.8253)$ & $( \pm 2.0500)$ & $( \pm 1.6206)$ \\
& 75.1000 & 79.1000 & 84.7000 & 76.1000 & 74.5333 \\
& $( \pm 2.0569)$ & $( \pm 2.0569)$ & $( \pm 3.0530)$ & $( \pm 2.0569)$ & $( \pm 1.9070)$ \\
& $\mathrm{F}=.079$ & $\mathrm{~F}=.149$ & $\mathrm{~F}=.1 .285$ & $\mathrm{~F}=.1 .074$ & $\mathrm{~F}=.762$ \\
& $\mathrm{~N} . \mathrm{S}$ & $\mathrm{N} . \mathrm{S}$ & $\mathrm{N} . \mathrm{S}$ & $\mathrm{N} . \mathrm{S}$ & $\mathrm{N} . \mathrm{S}$ \\
\hline
\end{tabular}

N.S- not significant 
Details of arterial blood pressure values, systolic, diastolic and mean are shown in Table VII,VIII\&IX. It can be seen that thiopentone caused some fall in systolic and little fall in diastolic blood pressure; mean arterial pressure consequently fall by an intermediate amount. Midazolam caused a greater decrease in systolic and diastolic blood pressure than thiopentone, but that was not significant. By contrast propofol caused a greater decrease in systolic blood pressure, which at 3 minutes after intubation had fallen by a mean of about $30 \mathrm{~mm}$ $\mathrm{Hg}$, and a considerable fall in diastolic blood pressure, with a fall of about $20 \mathrm{~mm} \mathrm{Hg}$. As a consequence, there was a considerable fall in mean arterial pressure. There was rise of blood pressure 1 minute after intubation in all the cases probably as a result of sympathetic stimulation due to intubation reflex.

Table VII Comparison of systolic blood pressure at different reading points

\begin{tabular}{lccccc}
\hline Group & $\begin{array}{c}\text { 2minutes } \\
\text { before } \\
\text { injection- } \\
\text { mean }( \pm \text { SD })\end{array}$ & $\begin{array}{c}\text { after } \\
\text { induction- } \\
\text { mean }( \pm \text { SD })\end{array}$ & $\begin{array}{c}\text { 1minute } \\
\text { after } \\
\text { intubation- } \\
\text { mean }( \pm \text { SD })\end{array}$ & $\begin{array}{c}\text { 3minutes } \\
\text { after } \\
\text { intubation- } \\
\text { mean }( \pm \text { SD })\end{array}$ & $\begin{array}{c}\text { 5minutes } \\
\text { after } \\
\text { intubation- } \\
\text { mean }( \pm \text { SD })\end{array}$ \\
\hline Thiopentone & 142.1000 & 138.1000 & 150.3000 & 129.1000 & 130.1000 \\
Midazolam & $( \pm 17.0746)$ & $( \pm 17.0746)$ & $( \pm 17.7009)$ & $( \pm 17.0825)$ & $( \pm 16.0126)$ \\
& 137.4333 & 132.4333 & 148.1000 & 125.4333 & 127.4333 \\
Propofol & $( \pm 14.5096)$ & $( \pm 13.1390)$ & $( \pm 17.0746)$ & $( \pm 14.5096)$ & $( \pm 14.1025)$ \\
& 145.2000 & 135.2000 & 142.8333 & 115.2000 & 120.2000 \\
& $( \pm 16.5413)$ & $( \pm 16.2415)$ & $( \pm 17.5501)$ & $( \pm 16.5413)$ & $( \pm 15.1360)$ \\
& $\mathrm{F}=1.773$ & $\mathrm{~F}=.932$ & $\mathrm{~F}=1.451$ & $\mathrm{~F}=6.021$ & $\mathrm{~F}=3.045$ \\
& $\mathrm{~N} . \mathrm{S}$ & $\mathrm{N} . \mathrm{S}$ & $\mathrm{N} . \mathrm{S}$ & $\mathrm{P}<0.01$ & $\mathrm{P}<0.05$ \\
\hline
\end{tabular}

N.S- not significant

Table VIII Comparison of diastolic blood pressure at different reading points

\begin{tabular}{lccccc}
\hline Group & $\begin{array}{c}\text { 2minutes } \\
\text { before } \\
\text { injection- } \\
\text { mean }( \pm \mathrm{SD})\end{array}$ & $\begin{array}{c}\text { after } \\
\text { induction- } \\
\text { mean }( \pm \mathrm{SD})\end{array}$ & $\begin{array}{c}\text { 1minute } \\
\text { after } \\
\text { intubation- } \\
\text { mean }( \pm \mathrm{SD})\end{array}$ & $\begin{array}{c}\text { 3minutes } \\
\text { after } \\
\text { intubation- } \\
\text { mean }( \pm \mathrm{SD})\end{array}$ & $\begin{array}{c}\text { 5minutes } \\
\text { after } \\
\text { intubation- } \\
\text { mean }( \pm \mathrm{SD})\end{array}$ \\
\hline Thiopentone & 78.7667 & 74.5000 & 80.6000 & 75.4333 & 75.3215 \\
& $( \pm 6.8917)$ & $( \pm 7.4776)$ & $( \pm 8.1351)$ & $( \pm 8.1988)$ & $( \pm 7.1897)$ \\
Midazolam & 81.5000 & 72.5000 & 80.5316 & 72.5315 & 72.8132 \\
& $( \pm 7.6010)$ & $( \pm 7.3215)$ & $( \pm 7.6218)$ & $( \pm 8.5369)$ & $( \pm 8.6758)$ \\
Propofol & 80.7000 & 70.5734 & 77.1333 & 58.7210 & 60.7000 \\
& $( \pm 7.3632)$ & $( \pm 7.3285)$ & $( \pm 6.9418)$ & $( \pm 7.3615)$ & $( \pm 7.3560)$ \\
F=1.937 & $\mathrm{F}=1.114$ & & $\mathrm{~F}=2.036$ & $\mathrm{~F}=36.980$ & $\mathrm{~F}=28.246$ \\
& $\mathrm{~N} . \mathrm{S}$ & $\mathrm{N} . \mathrm{S}$ & $\mathrm{N} . \mathrm{S}$ & $\mathrm{P}<0.001$ & $\mathrm{P}<0.001$ \\
\hline
\end{tabular}

N.S- not significant 
Table IX Comparison of mean blood pressure at different reading points

\begin{tabular}{lccccc}
\hline Group & $\begin{array}{c}\text { 2minutes } \\
\text { before } \\
\text { injection- } \\
\text { mean }( \pm \mathrm{SD})\end{array}$ & $\begin{array}{c}\text { after } \\
\text { induction- } \\
\text { mean }( \pm \mathrm{SD})\end{array}$ & $\begin{array}{c}\text { 1minute } \\
\text { after } \\
\text { intubation- } \\
\text { mean }( \pm \mathrm{SD})\end{array}$ & $\begin{array}{c}\text { 3minutes } \\
\text { after } \\
\text { intubation- } \\
\text { mean }( \pm \mathrm{SD})\end{array}$ & $\begin{array}{c}\text { 5minutes } \\
\text { after } \\
\text { intubation- } \\
\text { mean }( \pm \mathrm{SD})\end{array}$ \\
\hline Midazolam & 99.8778 & 95.7000 & 103.7222 & 93.3222 & 93.6556 \\
& $( \pm 8.0684)$ & $( \pm 8.5390)$ & $( \pm 7.5384)$ & $( \pm 9.3684)$ & $( \pm 9.3285)$ \\
Propofol & 100.1444 & 92.4778 & 103.0333 & 88.4778 & 89.3444 \\
& $( \pm 7.5011)$ & $( \pm 7.5210)$ & $( \pm 7.9978)$ & $( \pm 7.4744)$ & $( \pm 7.9565)$ \\
& 102.2000 & 92.2131 & 96.7444 & 77.5333 & 80.5314 \\
& $( \pm 7.9344)$ & $( \pm 7.8352)$ & $( \pm 8.5383)$ & $( \pm 7.9339)$ & $( \pm 7.8356)$ \\
& $\mathrm{F}=.789$ & $\mathrm{~F}=1.773$ & $\mathrm{~F}=6.870$ & $\mathrm{~F}=28.502$ & $\mathrm{~F}=18.812$ \\
\hline
\end{tabular}

N.S- not significant

There was no significant difference in the recovery times between thiopentone and propofol groups. However, patients in the midazolam group took much longer to recover $(\mathrm{p}>0.001)$. This is shown in Table X.

Table X Comparison of recovery time in seconds

\begin{tabular}{lccc}
\hline Group & Mean $( \pm \mathrm{SD})$ & F value & P value \\
\hline Thiopentone & $23.0333( \pm 3.2215)$ & & \\
Midazolam & $44.3667( \pm 7.8498)$ & 177.284 & $\mathrm{P}<0.001$ \\
Propofol & $21.8333( \pm 3.0971)$ & & \\
\hline
\end{tabular}

\section{Discussion}

There has always been a need for an intravenous anaesthetic agent possessing a good induction and recovery characteristics, particularly in elderly patients. Elderly people differ both anatomically and physiologically from normal healthy adults. Moreover, they have got significant pharmacokinetic and pharmacodynamic variability. ${ }^{1,9,10}$ Thiopentone is the most commonly used intravenous induction agent in elderly people. There was no significant difference in the time to loss of eye lash reflex in the propofol and thiopentone groups. This supports previous findings that the induction characteristics are similar with two agents. ${ }^{11,12}$ But Shah PJ et al found that induction was rapid with propofol as compared to thiopentone which was statistically significant. ${ }^{4}$ There was a sigficantly longer induction time with midazolam and this too in accordance with previous findings. $4,5,7$

The incidence of spontaneous movements was greater in the patients who had received propofol than in those who received thiopentone and midazolam. The incidence of movement and excitatory effects after induction with thiopentone and midazolam was insignificant.Previous study by Shah PJ et al found high incidence of gag reflex coughing, tearing, movement of limbs in thiopentone and midazolam groups compared to propofol. ${ }^{4}$ But Rahman MH et al showed that incidence of coughing was more in thiopentone group, which was absent with midazolam induction. Movement of limbs was more in midazolam group where as limb movement was seen only in 2 patients $(4 \%)$ in thiopentone group. Higher incidence of movement of limbs was probably because of slower induction with midazolam or inadequate dose of midazolam used for induction. ${ }^{5}$ Suri Y found no excitatory effects with midazolam and thiopentone. ${ }^{9}$

The incidence of pain on injection was significantly greater following propofol than after thiopentone and midazolam which was in consistent with previous findings. ${ }^{5,13}$ Shah PJ et al found that $20 \%$ of patients complained of pain on injection and $3.33 \%$ patients had thrombophlebitis with propofol compared $0 \%$ with thiopentone and midazolam. ${ }^{4}$ Rahman $\mathrm{MH}$ et al found that $14 \%$ of 
patients with thiopentone complained of pain on injection, where as $2 \%$ with midazolam. ${ }^{5}$ Suri Y found that no patients with either thiopentone or midazolam experienced any venous intolerance. ${ }^{9}$ In cases, where the drug was injected into a vein in the anticubital fossa, the incidence of pain was very low(3\%). ${ }^{12}$ This feature may prove to be a drawback to its use in ambulatory patients as they are usually unpremedicated and often very anxious.

The incidence of apnoea after induction with thiopentone and propofol was greater than that with midazolam. This was in consistent with previous findings. 5,7,9,11,12 This study has showed that thiopentone causes insignificant decrease in systolic, diastolic and mean blood pressure. There is no remarkable change in heart rate. Although midazolam caused a greater decrease in mean blood pressure compared to thiopentone, that was not clinically significant. Cardiovascular stability was satisfactory during the observation period. Though some study had reported a significant decrease in mean arterial blood pressure 2 minutes after induction with midazolam, it was probably due to relatively higher induction dose. ${ }^{11}$ There is however, a large variation in the recommended induction dose for midazolam $(0.2-0.4 \mathrm{mg} / \mathrm{kg})$. In this study propofol was found to have given a considerably greater fall in systolic, diastolic and mean blood pressure than did thiopentone. This persisted during the period under study in the propofol group. Earlier studies with propofol have reported similar results. ${ }^{12}$ This persistently low blood pressure is an obvious disadvantage in the use of propofol in patients with a compromised cardiac function as in elderly people and a low initial blood pressure who need to be cardioverted e.g. ventricular tachycardia. ${ }^{11,13}$ Singh et al found that in patients with left ventricular dysfunction, there was a significant decrease from the baseline in the heart rate, mean arterial pressure after induction in all three groups of patients. The thiopentone group recorded the least decrease in heart rate (-7\%), while the maximum decrease was seen in the midazolam group (-15\%). The decrease in mean arterial pressure ranged from -27 to $-32 \%$ and was similar across the three groups. ${ }^{3}$ In hypertensive patients with thiopentone and midazolam co-induction, patients with unstable heart rate and diastolic blood pressure were more likely in thiopentone group and patients with stable heart rate and diastolic blood pressure were more likely in co-induction group. ${ }^{6}$

The recovery times in this study suggested that there is no significant difference between propofol and thiopentone. Earlier study by Coolong KJ et al had similar result where the surgical procedure continued longer than 2 hours. ${ }^{10}$ This is in contrast to studies by Shah PJ et al and Henriksson BA et al which showed that propofol has significantly shorter recovery time than thiopentone. ${ }^{4,12}$ This could be explained by the very short procedures which they studied. In this study midazolam had a significantly longer recovery time than thiopentone and propofol. This is in consistent with previous findings. ${ }^{4,8,11}$ Previous study had showed that flumazenil was used to reverse its effects $15-30$ minutes after the induction of anaesthesia for cardioversion, and there was however, an acceptably high incidence (50\%) of resedation at the time of interview 4 hours later. ${ }^{11}$

\section{Conclusion}

Our findings suggest that thiopentone is the drug of choice for induction in elderly patients because of rapid induction, recovery and the least effect on arterial pressure. Propofol has no clear advantage over thiopentone and has the additional problem of a significant decrease in blood pressure. Midazolam, although safe, is clearly not the ideal drug for induction in elderly patients because of slow onset of action and delayed recovery.

\section{References}

1. Stoelting RK, Dierdorf SF. Anesthesia and coexisting disease $.5^{\text {th }}$ ed. Philadelphia: Churchill Livingstone; 2007. p. 639-49

2. Vickers MD, Morgan M, Spencer PSJ, Read MS. Drugs in anaesthetic and intensive care practice. $8^{\text {th }}$ ed. London: Butterworth Heinemann; 1999. p. 108-115

3. Singh R, Choudhury M, Kapoor PM, Kiran U. A randomized trial of anesthetic induction agents in patients with coronary artery disease and left ventricular dysfunction. Ann Card Anaesth 2010; 13: 217-23

4. Shah PJ, Dubey KP, Watti C, Lalwani J. Effectiveness of thiopentone, propofol and midazolam as an ideal intravenous anaesthetic agent for modified electroconvulsive therapy: 
A comparative study. Indian J Anaesth 2010; 54: 296-301

5. Nordt SP, Clark RF. Midazolam: a review of therapeutic uses and toxicity. J Emerg Med 1997; 15(3): 365-67

6. Rahman MH, Hassan M, Islam MM. Midazolam and thiopentone as co-induction. Journal of BSA 2004; 17: 23-27

7. Khan P, Zeb A, Rasool G. Comparative study of co-induction with thiopentone and midazolam versus thiopentone alone in hypertensive patients. JPMI 2007; 21(04): 266269

8. Pershad J, Wan J, Anghelescu DL. Comparison of propofol with pentobarbital/ midazolam/fentanyl sedation for Magnetic Resonance Imaging of the brain in children. PEDIATRICS 2007; 120(03): 629-635

9. Mathew PJ, Badhe A, Mathew JL. Comparison of induction and recovery characteristics of intravenous midazolam and thiopentone in paediatric halothane general anaesthesia. Acta Paediatr 2003; 92: 1211-13
10. Suri Y. Comparison of midazolam and thiopentone as induction agents in general anaesthesia. MJAFI 2001; 57: 213-214

11. Coolong KJ, McGough E, Vacchiano C, Pellegrini JE. Comparison of the effects of propofol versus thiopental induction on postoperative outcomes following surgical procedures longer than 2 hours. AANA journal 2003; 71(3): 215-221

12. Gupta A, Lennmarken C, Vegfors M, Tyden H. Anaesthesia for cardioverson: a comparison between propofol, thiopentone and midazolam. Anaesthesia 1990; 45: 872-75

13. Henriksson BA, Carlsson P, Hallen B, Hagerdal M, Lundberg D, Ponten J. Propofol vs thiopentone as anaesthetic agents for short operative procedures. Acta Anaesthesiologica Scandinavica 1987; 31: 63-66

14. Valtonen M, Kanto J, Klossner J. Anaesthesia for cardioversion: a comparison of propofol and thiopentone. Can J Anaesth 1988; 35: 479-83

15. Weightman WM, Zachariast M. Comparison of propofol and thiopentone anaesthesia (with special reference to recovery characteristics). Anaesth Intens Care 1987; 15: 389-93 